\title{
Synthesis and Properties of New Liquid Crystals as Curing Agents for Epoxy Resins
}

\author{
Anber M. Anber*, Sahar Al-Hariri, Ayham H. Abazid \\ Department of Chemistry, Faculty of Science, Damascus University, Damascus, Syrian Arab Republic \\ Email address: \\ anber1987@googlemail.com (A. M. Anber) \\ ${ }^{*}$ Corresponding author \\ To cite this article: \\ Anber M. Anber, Sahar Al-Hariri, Ayham H. Abazid. Synthesis and Properties of New Liquid Crystals as Curing Agents for Epoxy Resins. \\ American Journal of Applied Chemistry. Vol. 4, No. 6, 2016, pp. 247-255. doi: 10.11648/j.ajac.20160406.15
}

Received: December 4, 2016; Accepted: January 5, 2017; Published: January 20, 2017

\begin{abstract}
A novel class liquid crystalline epoxy resins was synthesized by reacting the diglycidyl ether of bisphenol A (DGEBA) with three new liquid crystal diols, 4,4'-di-N-[(6-hydroxy hexoxy)-3-pyridyl methylidene ]amino phenyl benzamide, 4,4 - di-N-[(6-hydroxy butoxy)-3-pyridyl methylidene]amino phenyl benzamide, and 4,4'- di-N-[(6-hydroxy etoxy)-3-pyridyl methylidene]amino phenyl benzamide, contain azomethine groups. The new liquid crystals were characterized by Fourier transformed infra-red (FT-IR) and nuclear magnetic resonance (NMR) spectroscopy. Flexibility and adhesion properties were then investigated for the cured resins based on new azomethine mesogenic diols. The cured polymers were found to exhibit high flexibility and good adhesion properties compared to ordinary amine systems.
\end{abstract}

Keywords: Epoxy Resin, Liquid Crystal, DGEBA, Schiff Base, Azomethine Mesogenic Diol, Synthesis, Characterization, Mechanical Properties

\section{Introduction}

Epoxies were widely use in industrial applications such as coatings, automotive primer, printed circuit boards, semiconductor encapsulants, adhesives, and composites. epoxy resins present the attractive characteristics of excellent mechanical strength and toughness; chemical, moisture, and corrosion resistance; good thermal, high adhesive, and superior electrical properties; no volatiles emission and low shrinkage upon cure; and excellent dimensional stability. In industrial, many commercial epoxies contain aliphatic, cycloaliphatic, aromatic backbones wide used with range of molecular weights. Bisphenol A is one of the most used in the synthesis of epoxies ( $>75 \%$ of resin sales volume), [1-2].

Several approaches were used in the past to control the crosslink density of an epoxy network. These include varying the epoxy resin curing agent functional group ratio, using a difunctional epoxy prepolymer with a different average chain length, and varying the molecular size of the difunctional curing agent, [3-5].

Liquid crystal thermosets based on this novel chemistry showed excellent combinations of thermal, mechanical, and chemical properties, unachievable with traditional epoxies, so many research groups have studied this epoxies, [6-12].

Lately, many compound of liquid crystalline thermosets with different mesogenic units and reactive end functional groups were prepared by Schiff bases and using in industry as curing agents for epoxies, [13-14].

Some of the epoxy resins produced showed mesomorphic states when the resins were fully cross-linked after hardening. The length of the mesogenic epoxy compound plays the main function in the appearance of a mesophase, [7], [15-18].

In this article, explores an efficient and economical process for preparing a new class of liquid crystals was described, where this class include Schiff bases. Moreover, we screen their activity as curing agents for synthesis the epoxy resins and using it in diverse applications. Also, we studied the effect of a different chain length methylene groups which prepared for the curing DGEBA and discussion the mechanical properties (flexibility and adhesion) for the cured resins. 


\section{Experimental}

\subsection{Materials}

4,4 '-diaminobenzanilide, ethoxyethane, Sodium carbonate, triethyl amine, butanol-1, DMF, 2-hydroxy-5-formylpridine, DGEBA, 6-chloro hexanol-1, 4-chloro butanol-1, 2-chloro etanol-1 were purchased from Sigma-Aldrich USA and used without further purification.

\subsection{Preparation of 4,4-di-N-[(6-Hydroxy Hexoxy)-3- Pyridyl Methylidene]Amino Phenyl Benzamide (I)}

\subsubsection{Synthesis of 4,4-di-N-[6-Hydroxy-3-Pyridyl Methylidene]Amino Phenyl Benzamide (I)}

2-hydroxy-5-formylpyridine ( $\left.4 \times 10^{-3} \mathrm{~mol}, 0.4924 \mathrm{~g}\right)$ and 4,4'-diaminobenzanilide ( $2 \times 10^{-3} \mathrm{~mol}, 0.4544 \mathrm{~g}$ ) were dissolved in (4)ml of ethanol in a $50 \mathrm{ml}$ round-bottomed flask. A catalytic amount of 4-toluenesulfoic acid in (1)ml ethanol was added dropwise to the flask and the mixture was stirred and refluxed for $6 \mathrm{~h}$. The resulting mixture was evaporated under reduced pressure to yield an off white solid, which was washed thoroughly with diethylether and dried under vacuum, $(0.7 \mathrm{~g})$ of crystal (m.p $136-137^{\circ} \mathrm{C}$, yield: $80 \%$ ) was obtained, Figure 1.

\subsubsection{Synthesis 4,4-di-N-[(6-Hydroxy Hexoxy)-3-Pyridyl Methylidene]Amino Phenyl Benzamide (I)}

(9 X $\left.10^{-4} \mathrm{~mol}, 0.0954 \mathrm{~g}\right)$ of anhydrous sodium carbonate and $\left(8 \times 10^{-4} \mathrm{~mol}, 0.1088 \mathrm{~g}\right)$ of 6-chloro hexanol-1 in (3)ml
DMF were put into a (50)ml three-necked round bottom flask equipped with a mechanical stirrer.

(4 X $10^{-4} \mathrm{~mol}, 0.175 \mathrm{~g}$ ) of 4,4 -di-N-[6-hydroxy-3-pyridyl methylidene ] amino phenyl benzamide ( $\left.\mathrm{I}^{\prime}\right)$, respectively was put into (2)ml of DMF, dissolved and added to the reactions flask slowly dropwise using an additional funnel. The reaction mixture was heated for $12 \mathrm{~h}$ at $130^{\circ} \mathrm{C}$, and cooled. The cooled mixture was poured into $(25) \mathrm{ml}$ of cold water, then the solid product was filtered by using Buchner funnel.

The solid product was washed by water and dried at $70^{\circ} \mathrm{C}$ under vacuum for $24 \mathrm{~h}$. After drying, it was recrystallized in mixture of DMF and butanol-1 (1:1). The crystallized product was washed by ethyl ether and dried at $90^{\circ} \mathrm{C}$ under vacuum for an additional 24h. (0.1784g, m.p 101-102 ${ }^{\circ} \mathrm{C}$, yield: $70 \%$, off white solid), Figure 1.

FT-IR (KBr, cm $\left.{ }^{-1}\right): 3560 \mathrm{~cm}^{-1}(\mathrm{O}-\mathrm{H}), 3430 \mathrm{~cm}^{-1}(\mathrm{~N}-\mathrm{H})$, $2890 \mathrm{~cm}^{-1}$ and $2950 \mathrm{~cm}^{-1}$ (C-H aliphatic), $1660 \mathrm{~cm}^{-1}(\mathrm{C}=\mathrm{O})$, $1620 \mathrm{~cm}^{-1}(\mathrm{C}=\mathrm{N}), 1270 \mathrm{~cm}^{-1}$ and $1180 \mathrm{~cm}^{-1}(\mathrm{C}-\mathrm{O}) . \delta_{\mathrm{H}}(400$ MHz, $d$-DMSO) $\delta: 9.33(\mathrm{~s}, 1 \mathrm{H}), 9.24(\mathrm{~s}, 2 \mathrm{H}), 8.26(\mathrm{~d}, 2 \mathrm{H}, J$ $=4.0 \mathrm{~Hz}), 7.95(\mathrm{~s}, 2 \mathrm{H}), 7.85(\mathrm{~d}, 2 \mathrm{H}, J=8.0 \mathrm{~Hz}), 7.53(\mathrm{dd}, 4$ $\mathrm{H}, J=4.0 \mathrm{~Hz}, J=12.0 \mathrm{~Hz}), 7.43(\mathrm{~d}, 2 \mathrm{H}, J=4.0 \mathrm{~Hz}), 6.64(\mathrm{~d}$, $2 \mathrm{H}, J=8.0 \mathrm{~Hz}), 4.34(\mathrm{t}, 4 \mathrm{H}, J=8.0 \mathrm{~Hz}), 3.75(\mathrm{~s}, 2 \mathrm{H}), 3.65(\mathrm{t}$, $4 \mathrm{H}, J=8.0 \mathrm{~Hz}) . \delta_{\mathrm{C}}(100 \mathrm{MHz}, d$-DMSO) $\delta: 166.34,164.12$, $158.78,147.85,145.97,139.24,137.73,136.69,128.05$, $127.82,122.11,121.15,105.15,104.30,104.01,75.42,60.48$, figure 5 .

Elem. Anal. Calcd.(\%) for $\mathrm{C}_{37} \mathrm{H}_{43} \mathrm{~N}_{5} \mathrm{O}_{5}$ : C, 69.68; H, 6.08; N, 10.98; Found: C, 69.55; H, 6.11; N, 10.95.

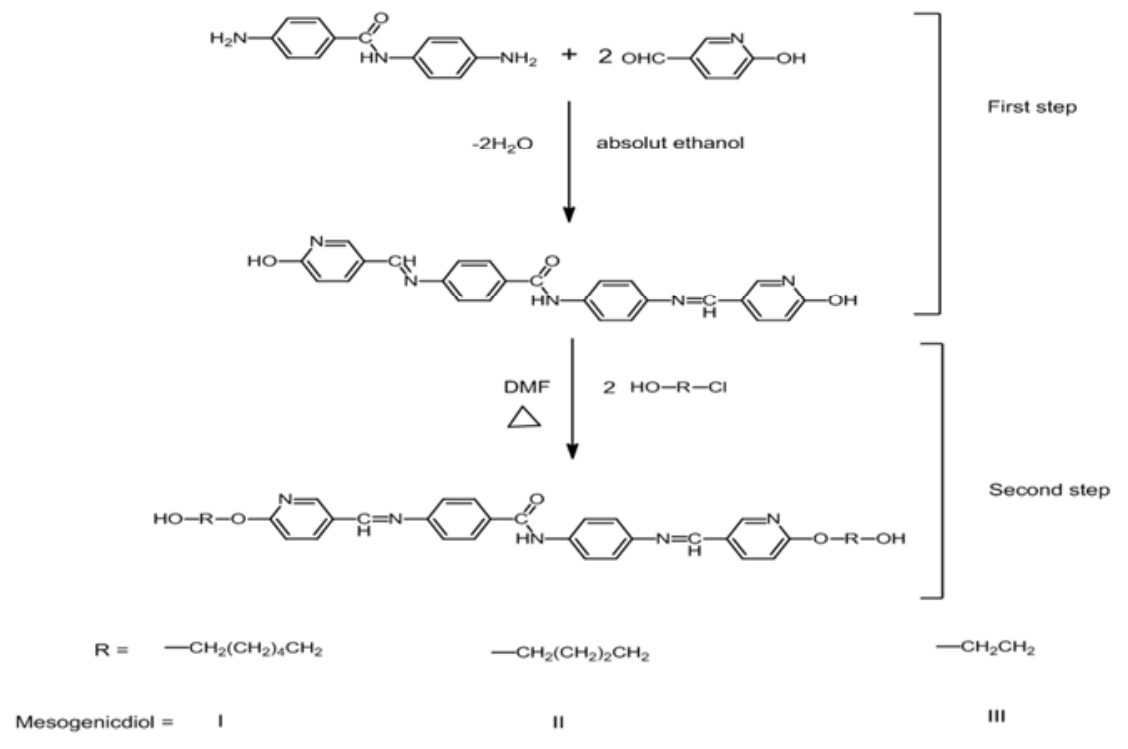

Figure 1. Synthesis of liquid crystals (I)(II)(III).

\subsection{Preparation of 4,4-di-N-[(6-Hydroxy Butoxy)-3- Pyridyl Methylidene]Amino Phenyl Benzamide (II)}

(9 X $10^{-4} \mathrm{~mol}, 0.0954 \mathrm{~g}$ ) of anhydrous sodium carbonate and (8 X 10 $\left.0^{-4} \mathrm{~mol}, 0.1011 \mathrm{~g}\right)$ of 4-chloro butanol-1 (86\%) in (3) $\mathrm{ml} \mathrm{DMF}$ were put into a $(50) \mathrm{ml}$ three-necked round bottom flask equipped with a mechanical stirrer.

$\left(4 \times 10^{-4} \mathrm{~mol}, 0.175 \mathrm{~g}\right)$ of 4,4 -di-N-[6-hydroxy-3-pyridyl methylidene]amino phenyl benzamide ( $\left.\mathrm{I}^{\prime}\right)$, respectively was put into (2)ml of DMF, dissolved and added to the reactions flask slowly dropwise using an additional funnel. The reaction mixture was heated for $12 \mathrm{~h}$ at $130^{\circ} \mathrm{C}$, and cooled. The cooled mixture was poured into $(25) \mathrm{ml}$ of cold water, then the solid product was filtered by using Buchner funnel.

The solid product was washed by water and dried at $70^{\circ} \mathrm{C}$ under vacuum for $24 \mathrm{~h}$. After drying, it was recrystallized in mixture of DMF and butanol-1 (1:1). The crystallized 
product was washed by ethyl ether and dried at $90^{\circ} \mathrm{C}$ under vacuum for an additional $24 \mathrm{~h}$. $\left(0.1278 \mathrm{~g}, \mathrm{~m} . \mathrm{p} 109^{\circ} \mathrm{C}\right.$, yield: $55 \%$, off white solid), Figure 1.

FT-IR (KBr, cm $\left.{ }^{-1}\right): 3510 \mathrm{~cm}^{-1}(\mathrm{O}-\mathrm{H}), 3400 \mathrm{~cm}^{-1}(\mathrm{~N}-\mathrm{H})$, $2870 \mathrm{~cm}^{-1}$ and $2960 \mathrm{~cm}^{-1}$ (C-H aliphatic), $1660 \mathrm{~cm}^{-1}(\mathrm{C}=\mathrm{O})$, $1625 \mathrm{~cm}^{-1}(\mathrm{C}=\mathrm{N}), 1280 \mathrm{~cm}^{-1}$ and $1190 \mathrm{~cm}^{-1}(\mathrm{C}-\mathrm{O}) . \delta_{\mathrm{H}}(400$ $\mathrm{MHz}, d$ - DMSO) $\delta: 9.14(\mathrm{~s}, 1 \mathrm{H}), 9.13(\mathrm{~s}, 2 \mathrm{H}), 8.55(\mathrm{~s}, 2 \mathrm{H})$, $8.25(\mathrm{~d}, 2 \mathrm{H}, J=4.0 \mathrm{~Hz}), 7.85(\mathrm{~d}, 2 \mathrm{H}, J=8.0 \mathrm{~Hz}), 7.57$ (dd, 4 $\mathrm{H}, J=4.0 \mathrm{~Hz}, J=12.0 \mathrm{~Hz}), 7.39(\mathrm{~d}, 2 \mathrm{H}, J=4.0 \mathrm{~Hz}), 6.85(\mathrm{~d}$, $2 \mathrm{H}, J=8.0 \mathrm{~Hz}), 4.24(\mathrm{t}, 4 \mathrm{H}, J=8.0 \mathrm{~Hz}), 3.65(\mathrm{~s}, 2 \mathrm{H}), 3.45(\mathrm{t}$, $4 \mathrm{H}, J=8.0 \mathrm{~Hz}), 1.68-1.76(\mathrm{~m}, 4 \mathrm{H}), 1.34-1.58(\mathrm{~m}, 4 \mathrm{H}) . \delta_{\mathrm{C}}$ (100 MHz, $d$ - DMSO) $\delta: 166.69,164.12,159.78,148.85$, $147.22,142.73,138.82,137.15,131.73,131.69,126.32$, $124.61,123.15,112.30,112.22,66.34,60.73,22.61,21.12$, figure 6 .

Elem. Anal. Calcd.(\%) for $\mathrm{C}_{33} \mathrm{H}_{35} \mathrm{~N}_{5} \mathrm{O}_{5}$ : C, 68.14; $\mathrm{H}, 6.07$; N, 12.04; Found: C, 68.06; H, 6.01; N, 11.98 .

\subsection{Preparation of 4,4-di-N-[(6-Hydroxy Etoxy)-3-Pyridyl Methylidene]Amino Phenyl Benzamide (III)}

$\left(9 \times 10^{-4} \mathrm{~mol}, 0.0954 \mathrm{~g}\right)$ of anhydrous sodium carbonate and $\left(8 \times 10^{-4} \mathrm{~mol}, 0.0645 \mathrm{~g}\right)$ of 2 -chloro etanol-1 in (3)ml DMF were put into a (50)ml three-necked round bottom flask equipped with a mechanical stirrer.

(4 X $10^{-4} \mathrm{~mol}, 0.175 \mathrm{~g}$ ) of 4,4'- di-N-[6-hydroxy-3pyridyl methylidene] amino phenyl benzamide (I'), respectively was put into (2)ml of DMF, dissolved and added to the reactions flask slowly dropwise using an additional funnel. The reaction mixture was heated for $12 \mathrm{~h}$ at $130^{\circ} \mathrm{C}$, and cooled. The cooled mixture was poured into $(25) \mathrm{ml}$ of cold water, then the solid product was filtered by using Buchner funnel.

The solid product was washed by water and dried at $70^{\circ} \mathrm{C}$ under vacuum for $24 \mathrm{~h}$. After drying, it was recrystallized in mixture of DMF and butanol-1 (1:1). The crystallized product was washed by ethyl ether and dried at $90^{\circ} \mathrm{C}$ under vacuum for an additional $24 \mathrm{~h}$. $\left(0.1365 \mathrm{~g}, \mathrm{~m} . \mathrm{p} 124^{\circ} \mathrm{C}\right.$, yield: $65 \%$, off white solid), Figure 1 .

FT-IR (KBr, cm$\left.{ }^{-1}\right): 3540 \mathrm{~cm}^{-1}(\mathrm{O}-\mathrm{H}), 3480 \mathrm{~cm}^{-1}(\mathrm{~N}-\mathrm{H})$, $2870 \mathrm{~cm}^{-1}$ and $2950 \mathrm{~cm}^{-1}$ (C-H aliphatic), $1660 \mathrm{~cm}^{-1}(\mathrm{C}=\mathrm{O})$, $1620 \mathrm{~cm}^{-1}(\mathrm{C}=\mathrm{N}), 1270 \mathrm{~cm}^{-1}$ and $1190 \mathrm{~cm}^{-1}(\mathrm{C}-\mathrm{O}) . \delta_{\mathrm{H}}(400$ MHz, $d$ - DMSO) $\delta: 9.28(\mathrm{~s}, 1 \mathrm{H}), 9.18(\mathrm{~s}, 2 \mathrm{H}), 8.58(\mathrm{~s}, 2 \mathrm{H})$, $8.27(\mathrm{~d}, 2 \mathrm{H}, J=8.0 \mathrm{~Hz}), 7.87(\mathrm{~d}, 2 \mathrm{H}, J=4.0 \mathrm{~Hz}), 7.61(\mathrm{dd}, 4$ $\mathrm{H}, J=4.0 \mathrm{~Hz}, J=12.0 \mathrm{~Hz}), 7.40(\mathrm{~d}, 2 \mathrm{H}, J=8.0 \mathrm{~Hz}), 6.91(\mathrm{~d}$, $2 \mathrm{H}, J=8.0 \mathrm{~Hz}), 4.26(\mathrm{t}, 4 \mathrm{H}, J=8.0 \mathrm{~Hz}), 3.65(\mathrm{~s}, 2 \mathrm{H}), 3.46(\mathrm{t}$, $4 \mathrm{H}, J=8.0 \mathrm{~Hz}), 1.78-1.86(\mathrm{~m}, 4 \mathrm{H}), 1.33-1.42(\mathrm{~m}, 12 \mathrm{H}) . \delta_{\mathrm{C}}$ (100 MHz, $d$ - DMSO) $\delta$ : 168.30, 166.30, 162.34, 154.85, $153.22,147.11,139.82,137.15,132.36,131.96,125.77$, $123.44,122.53,112.63,112.16,66.60,60.36,28.32,27.69$, 22.53, 21.41, figure 7 .

Elem. Anal. Calcd.(\%) for $\mathrm{C}_{29} \mathrm{H}_{27} \mathrm{~N}_{5} \mathrm{O}_{5}$ : C, 66.27; H, 5.18; N, 13.33; Found: C, 66.21; H, 5.23; N, 13.24.

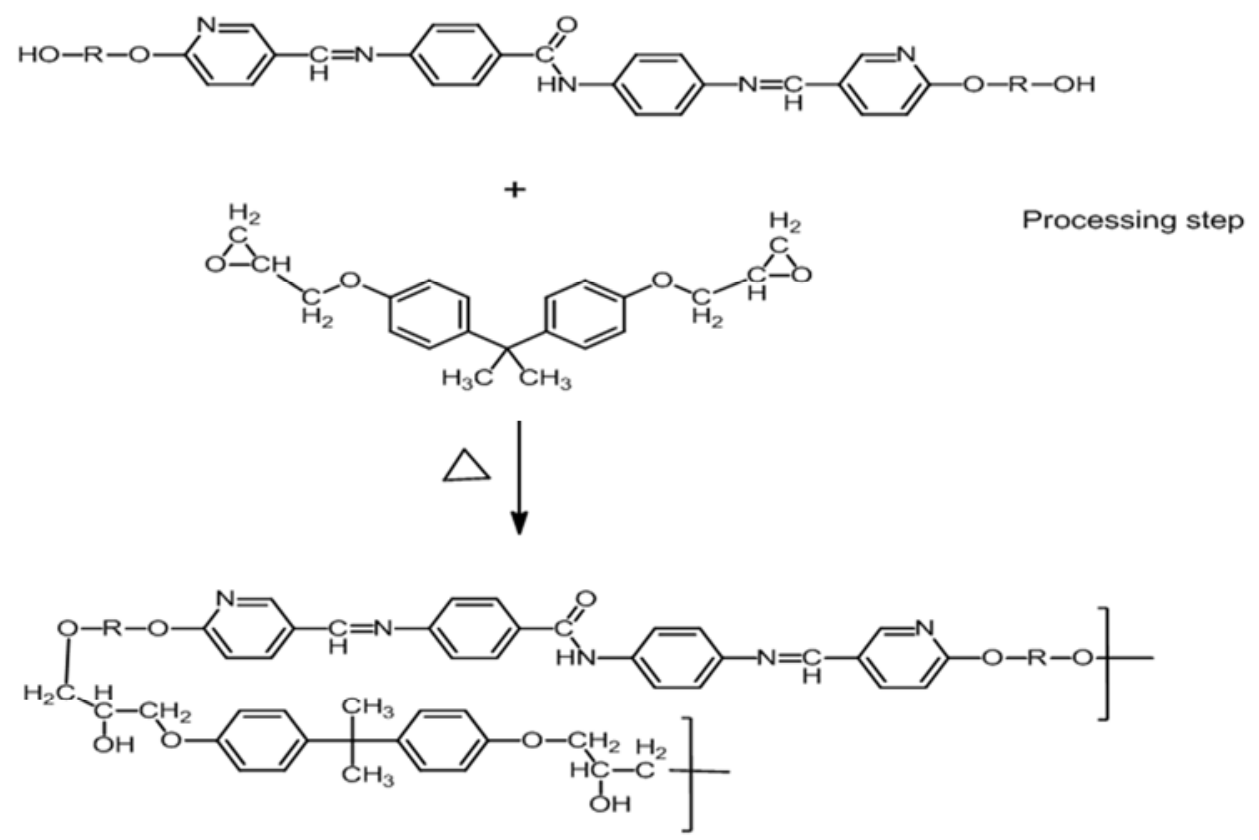

Figure 2. Cure reaction between DGEBA and liquid crystals (I)(II)(III).

\subsection{Cure Reaction Between DGEBA and Liquid Crystals Diols}

The cure reaction between epoxy resin DGEBA and liquid crystals was carried out with the mole ratio (1:1) of DGEBA to liquid crystal. To start the cure reaction, appropriate quantities of DGEBA and liquid crystal were mixed well in an aluminum panel $(5 \times 10 \mathrm{~cm})$, and $(3 \%)$ triethylamine, with respect to the weight of the liquid crystal, was then also added to the panel. The panel was placed in an air-circulated oven at $150^{\circ} \mathrm{C}$ for $1 \mathrm{~h}$. The cure resins were then used for mechanical studies, Figure 2.

\subsection{Instrumentation}

NMR spectra were recorded on a Bruker-Avance 400-MHz spectrometer. The residual solvent protons $\left({ }^{1} \mathrm{H}\right)$ or the solvent 
carbon $\left({ }^{13} \mathrm{C}\right)$ were used as internal standards. $\mathrm{CDCl} 3$ was used as the solvent and TMS as the internal reference. Infrared (IR) spectra were recorded on a Vertex 80/80v (FTIR) spectrometer using samples in $\mathrm{KBr}$ pellets.

\subsection{Mechanical Studies}

\subsubsection{Coating Flexibility Test}

This test method (ASTM D4145-83 Reapproved 2002) describes a procedure for determining the flexibility and adhesion of organic coatings (paints) on metallic substrates that are deformed by bending when the sheet is fabricated into building panels or other products. The metal substrate must be passing this test without fracturing and with no excessive grain development. Prepainted panels are bent 180 around progressively more thicknesses of metal or larger diameter dies, the end point being when failures no longer occur. The panels are examined at low magnification $(5 \times 10 \mathrm{~cm})$ after each bend for fracture of the coating (cracking) and for loss of adhesion pickoff, by means of a tape pull-off test, figure 3 . This test is a means of evaluating the ability of a coating system to withstand the stresses of fabrication [19].

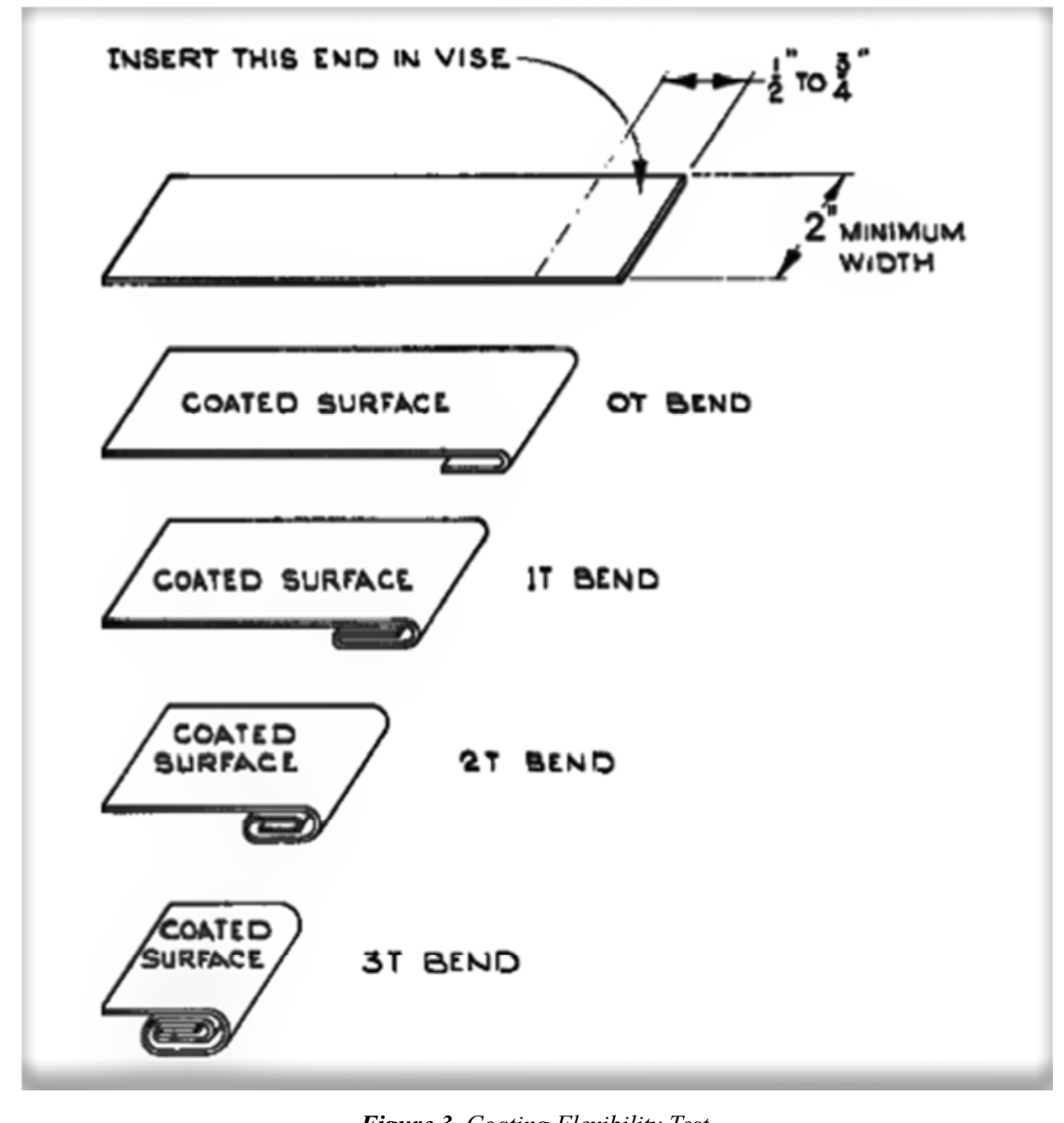

Figure 3. Coating Flexibility Test.

\subsubsection{Coating Adhesion Test}

These test method (ASTM D 3359-97-B) procedures for assessing the adhesion of coating films to metallic substrates by applying and removing pressure-sensitive tape over cuts made in the film. These test methods are used to establish whether the adhesion of coating to a substrate is at a generally adequate level. Test Method-A lattice pattern with either six or eleven cuts in each direction is made in the film to the substrate, pressure-sensitive tape is applied over the lattice and then removed, figure 4. and adhesion is evaluated by comparison with descriptions and illustrations, [20].

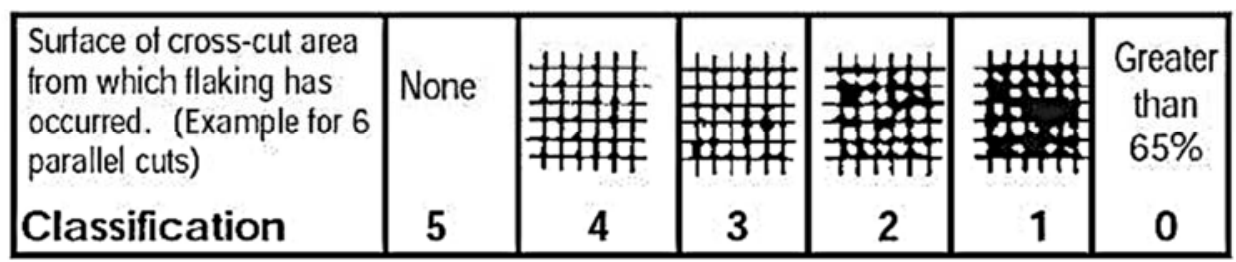

5: none, $4:(<5 \%), 3:(5-15 \%), 2:(15$ to $35 \%), 1:(35-65 \%), 0:(>65 \%)$.

Figure 4. Coating Adhesion Test. 


\section{Results and Discussions}

\subsection{Synthesis and Characterization of Mesogenic Diols I, II, III}

3.1.1. Spectra of 4,4 -di-N-[(6-Hydroxy Hexoxy)-3-Pyridyl Methylidene]Amino Phenyl Benzamide (I)
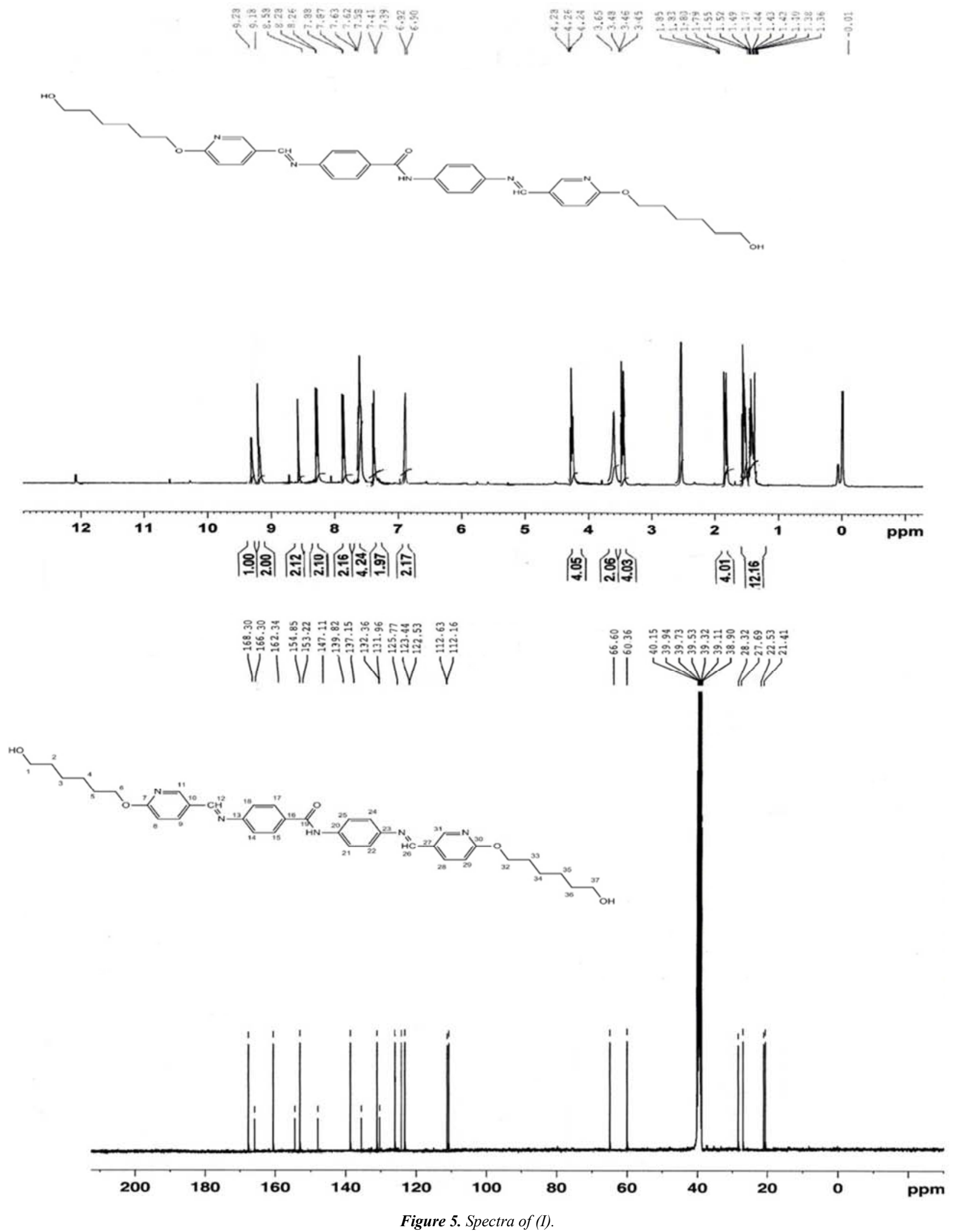


\subsubsection{Spectra of 4,4 -di-N- (6-Hydroxy Butoxy)-3-Pyridyl Methylidene]Amino Phenyl Benzamide (II)}

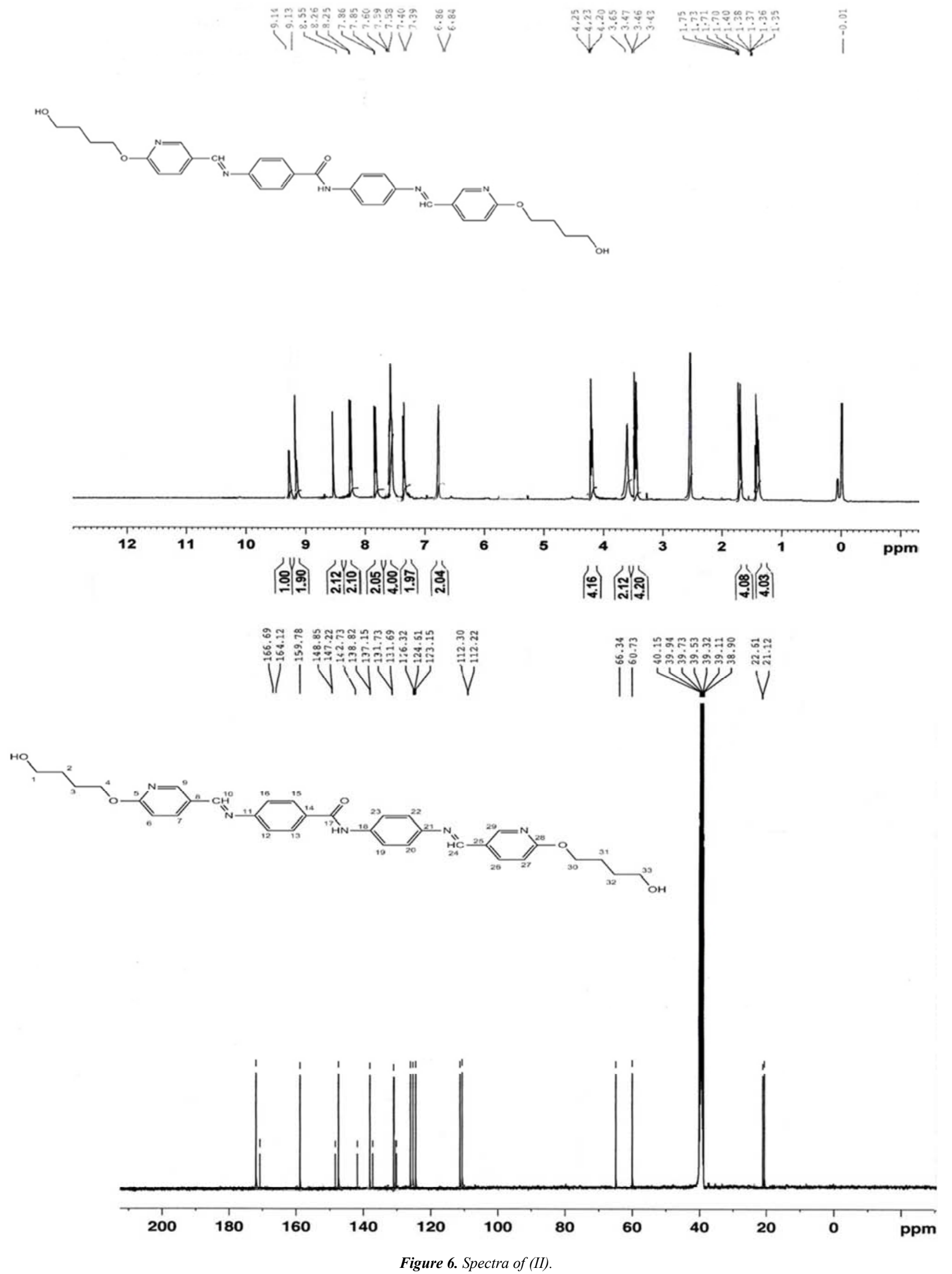


3.1.3. Spectra for 4,4`-di-N-[(6-Hydroxy Etoxy)-3-Pyridyl Methylidene]Amino Phenyl Benzamide (III)
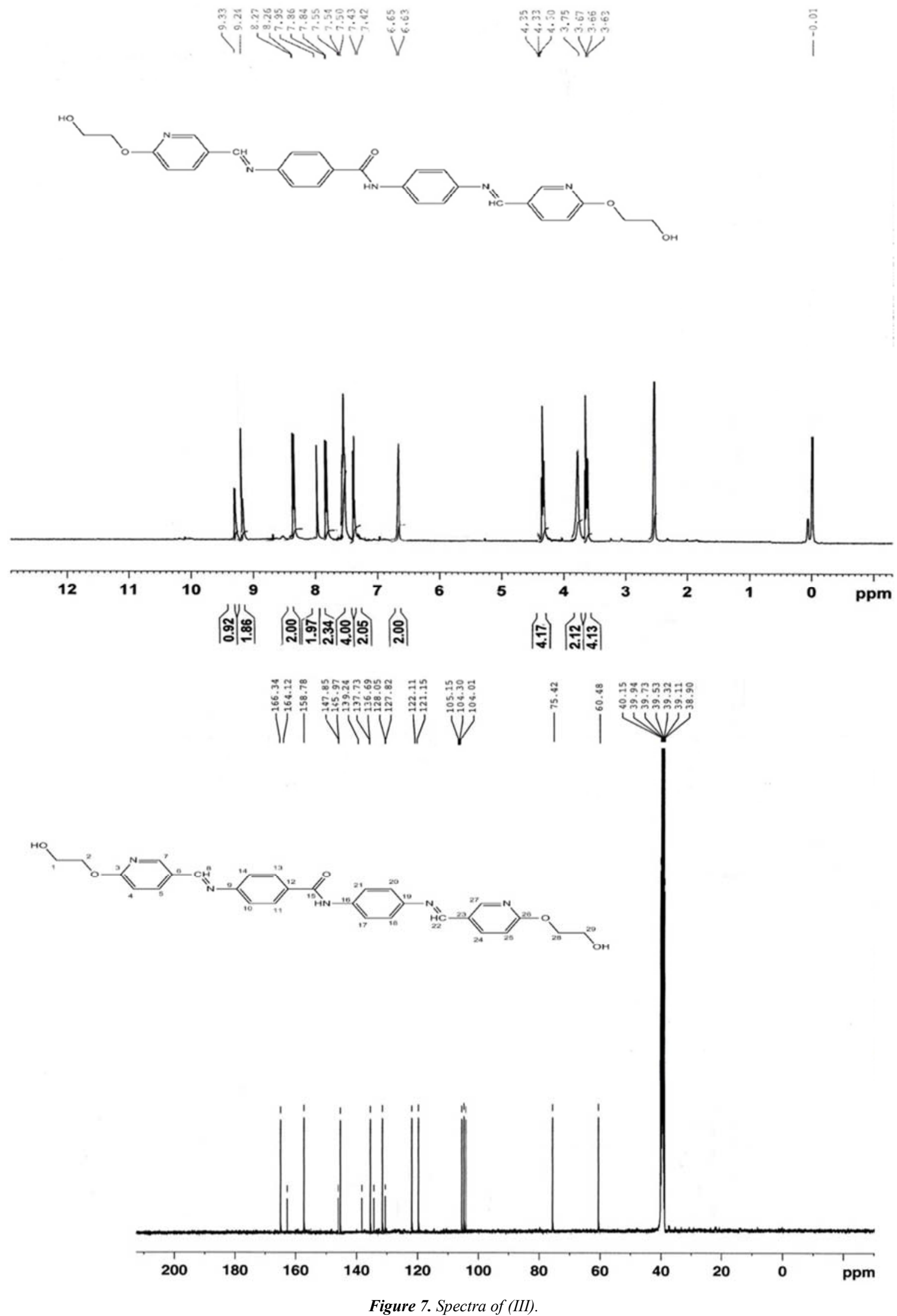


\subsubsection{IR Spectra for 4,4`-di-N-[(6-Hydroxy Hexoxy)-3-Pyridyl Methylidene]Amino Phenyl Benzamide (I)}

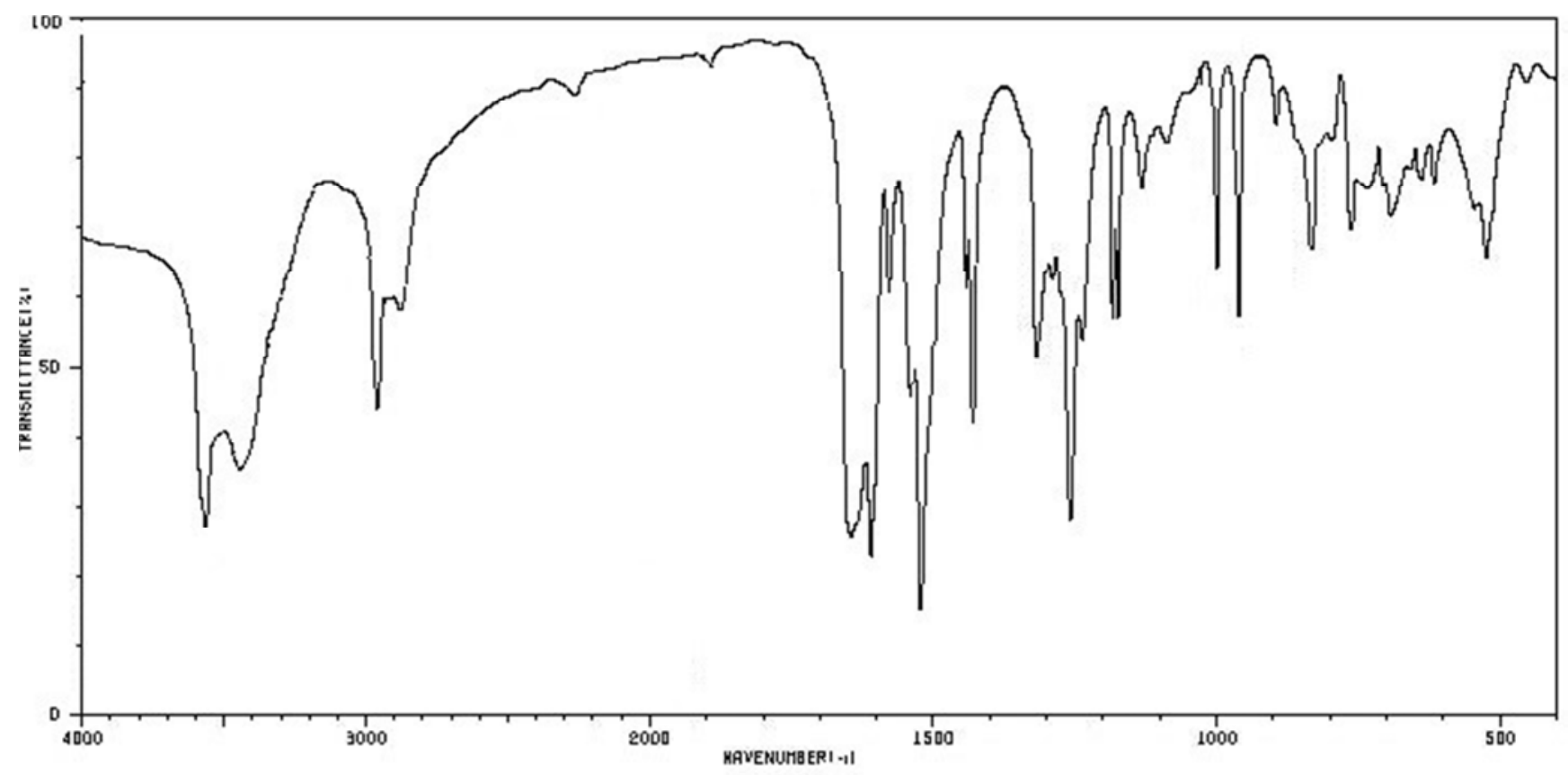

Figure 8. IR Spectra of (I).

The FT-IR spectra of liquid crystal (I) is given in figure 8, which shows the absorption band at $1620 \mathrm{~cm}^{-1}$, indicating the presence of a $(-\mathrm{CH}=\mathrm{N}-)$ group. The peaks at $1540 \mathrm{~cm}^{-1}$ and $1580 \mathrm{~cm}^{-1}$ were assigned to aromatic ring $(-\mathrm{C}=\mathrm{C}-)$ stretching. In addition, the $(\mathrm{C}=\mathrm{O})$ was positioned at $1660 \mathrm{~cm}^{-1}$, and the (-OH) stretching band at $3560 \mathrm{~cm}^{-1}$. The absorption bands at $2890 \mathrm{~cm}^{-1}$ and $2950 \mathrm{~cm}^{-1}$ were assigned to aliphatic group (C-H). The absorption bands at $1020 \mathrm{~cm}^{-1}$ and $1270 \mathrm{~cm}^{-1}$ indicating the presence of a $(\mathrm{C}-\mathrm{O})$ group. The ${ }^{1} \mathrm{H}$ NMR spectra of azomethine liquid crystals I, II and III are shown in figure 5, figure 6 and figure 7, respectively. Figure 5 shows the presence of a peak at $9.18 \mathrm{ppm}$ that confirmed the existence of the azomethine group $(-\mathrm{CH}=\mathrm{N})$. Tow characteristic peaks centered at 3.65 and $4.26 \mathrm{ppm}$ corresponded to $(-\mathrm{OH})$ and $\left(-\mathrm{CH}_{2}-\mathrm{O}\right)$, respectively, further confirming the formation of the desired azomethine liquid crystal.

\subsection{Mechanical Properties}

\subsubsection{Coating Flexibility Test}

The result revealed that the cured resin films exhibited high flexibility compared to amine curing systems. The cured resin with liquid crystals (III) Was cracked at (3T), but with liquid crystal (II) and liquid crystal (I) weren`t cracked at (3T), this flexibility was attributed to the incorporation of chain length methylene groups in the liquid crystals (II) and (I).

\subsubsection{Coating Adhesion Test}

The cured resin DGEBA with liquid crystal diol (I), (II) and (III) showed high adhesion properties compared to ordinary amine systems, the result of all cured resin tests were (5).

\section{Conclusions}

New liquid crystals that can be used as curing agents for epoxy resin (DGEBA) were successfully Prepared and characterized by means of NMR and FT-IR spectra. The flexibility and adhesion properties of cured polymers were studied by test methods of ASTM D4145-83 and ASTM D3359-97-B. These cured resins were found to exhibit high flexibility, electrical properties, low shrinkage upon cure, dimensional stability and good adhesion properties. These products could use in wide applications: semiconductor encapsulants, printed circuit boards and aerospace composites.

In the future, we will prepare new types of liquid crystal by using the heterocyclic rings and studying their thermal, mechanical, and chemical properties.

\section{Acknowledgement}

We are grateful to Damascus university, department of chemistry. Especially, Dr. Farouk Kandil and Dr. Thanaa AlHaddad for helping us for naming our compound.

\section{References}

[1] S. J. Hartman, The Epoxy Resin Formulators Training Manual, The Society of the Plastics Industry, Inc., New York, 1984; 9, 678-679.

[2] Fan-Long Jin, Xiang Li, Soo-Jin Park, Synthesis and application of epoxy resins: A review, Journal of Industrial and Engineering Chemistry, 2015; 29, 1-11. 
[3] Pooja Sharma, Thermal behaviour of Diglycidyl ether of bisphenol-A (DGEBA)/dithiols bearing an azomethine group: International Journal of Chem Tech Research, Jan-Mar 2013; 5 (1), 85-91.

[4] V. Ambrogi, M. Giamberini, P. Cerruti, P. Pucci, N. Menna, R. Mascolo, C. Carfagna, Liquid crystalline elastomers based on diglycidyl terminated rigid monomers and aliphatic acids. Part 1. Synthesis and characterization, Polymer, 2005; 46, 7, 2105 2121.

[5] Yin-Ling Liu, Zhi-Qi Cai, X. Wen, P. Pi, D. Zheng, J. Cheng, $Z$. Yang, Thermal properties and cure kinetics of a liquid crystalline epoxy resin with biphenyl-aromatic ester mesogen, Thermochimica Acta, 513, 2011; 1-2, 88-93.

[6] C. Farren, M. Akatsuka, Y. Takezawa, Y. Itoh, Thermal and mechanical properties of liquid crystalline epoxy resins as a function of mesogen concentration: Polymer, 2001, 42, 1507.

[7] C. Carfagna, E. Amendola, M. Giamberini, Liquid crystalline epoxy resins containing binaphthyl group as rigid block with enhanced thermal stability: Macromolecular Chemistry and Physics, 1994; 195, 2307.

[8] K. Sadagopan, D. Ratna, A. B. J. Samui, Synthesis and characterization of liquid-crystalline epoxy and its blend with conventional epoxy: Journal of Polymer Science Part A, 2003, 41,3375 .

[9] J. Y. Lee, S. S. Hong, K. U. Kim, Relationship between the structure of the bridging group and curing of liquid crystalline epoxy resins: Polymer, 1999, 40, 3197-3202.

[10] E. J. Choi, J. C. Seo, H. K. Bae, J. K. Lee, Synthesis and curing of new aromatic azomethine epoxies with alkoxy side groups: Eur. Polym, 2004; 40, 259-265.

[11] M. Brehmer, R. Zentel, Liquid Crystalline ElastomersCharacterization as Networks: Journal Molecular Crystals and Liquid Crystals Science and Technology Section A. Molecular Crystals and Liquid Crystals, 1994; 243, 353.
[12] C. W. Tsaia, K. H. Wub, C. C. Yangc, G. P. Wang, Adamantane-based epoxy resin and siloxane-modified adamantane-based epoxy resin: Characterization of thermal, dielectric and optical properties, Reactive and Functional Polymers, 2015; 91-92, 11-18.

[13] J. J. Mallon, P. M. Adams, Synthesis and characterization of novel epoxy monomers and liquid crystal thermosets, Journal of Polymer Science Part A: Polymer Chemistry, 1993; 31, 2249.

[14] Z. Gao, Y. Yu, Y. Xu, S. Li., Synthesis and characterization of a liquid crystalline epoxy containing azomethine mesogen for modification of epoxy resin: Journal of Applied Polymer Science, 2007; 105, 1861-1868.

[15] I. A. Mohammad, M. F. Ali, W. S. Wan Daud, New class of liquid crystalline epoxy resins: Synthesis and properties: Journal of Industrial and Engineering Chemistry, 2012; 18, 364-372.

[16] E.-Joon Choi, Hung-Kun Ahn, Jong Keun Lee, Jung-Il Jin, Liquid crystalline twin epoxy monomers based on azomethine mesogen: synthesis and curing with aromatic diamines, Polymer, 2000; 41, 21, 7617-7625.

[17] Yong-Ho Ahn, Myung-Sup Jung, Jin-Hae Chang, Synthesis and characterization of liquid crystals and their thermoset films, Materials Chemistry and Physics, 2010; 123, 1, 177183.

[18] H. Wang, Y. Zhang, L. Zhu, Z. Du, B. Zhang, Y. Zhang, Curing behaviors and kinetics of epoxy resins with a series of biphenyl curing agents having different methylene units, Thermochimica Acta, 521, 2011; 1-2, 18-25.

[19] ASTM Designation, D 4145-83, Standard Test Method for Coating Flexibility of Prepainted Sheet, 1983, Reapproved 2002; $1-3$

[20] ASTM Designation, D 3359-97, Standard Test Methods for Measuring Adhesion by Tape Test, 1997; 1-10. 